\title{
Risk of North Pole Route on Suez Canal Revenue
}

\author{
Capt. Ahmed Dawood ${ }^{1}$ and Capt. Ahmed Sharabia ${ }^{2}$ \\ 1. Lecturer of Navigation in the Department of Nautical Studies, Arab Academy for Science, Technology and Maritime \\ Transportation, Alexandria 21937, Egypt
}

2. Lecturer of Seaman Ship and Marine Safety in Sea Training Institute, Arab Academy for Science, Technology and Maritime Transportation, Alexandria 21937, Egypt

\begin{abstract}
The inauguration of the North Pole route as an alternate route for transporting cargoes between the Far East and Europe appears to be extremely acceptable by shipping companies owing to the huge saving in fuel consumption, bunker cost, operating cost, emissions and journey time. This route conversion will not only have an impact on the maritime business activity in the Suez Canal, but also the Egyptian economy in several aspects when the number of vessels passing through the Suez Canal and the Indian Ocean decreases. The aim of this study is to analyze the impact of the opening of the Northern Sea route on maritime sector of the Egyptian economy. The scope of this study is concentrating on the Suez Canal shipping activity by using the statistics that have been received from Suez Canal Authority through a set of direct and indirect interview sessions with authority's experts.
\end{abstract}

Key words: Suez, pole, cargo, arctic, revenue.

\section{Introduction}

Egypt's geographical location is a vital aspect to the maritime transport sector. Overlooking both the Red and the Mediterranean seas which are connected by the Suez Canal, Egypt recognized its role at the international level. The government developed the infra structure of the maritime industry by constructing ports and providing them with high-tech equipments to deal with passengers and cargoes [1].

Egyptian ports have witnessed a slight development. Egypt has many maritime facilities on both coasts of the Red and the Mediterranean seas.

Egypt has 15 commercial ports, 51 specialized ports (6 specializing in tourism, 15 specializing in oil, 9 specialized in mining, 21 specialized in fishing and 17 berths), six ports overlooking the Mediterranean Sea and other nine overlooking the Red Sea. The four main ports include: the multi-purpose Alexandria port which is considered as the largest port in Egypt, the Suez port which is used in the transfer of $60 \%$ of the country's foreign trade. The East Port Said and Damietta ports

Corresponding author: Captain Ahmed Dawood, master, research field: maritime safety and security. are the largest container ports in Egypt.

The Port Said port authority is considered the highest ports authority in Egypt according to the number of traded containers in the Egyptian ports, as it is used in the trading of $59.3 \%$ of the total traded containers in the Egyptian ports in 2011. The port is used as a hub for shipping transit regions which is used in container handling, while the Suez port plays an important role in both the cargo handling operations and the pass of ships through the Suez Canal [2].

The Egyptian government has focused on the development of ports and raising its standards to occupy larger ships comparing to those which pass through them, and to increase their capacity to be used in larger extent of trade. In 2011, the number of containers handled in Egyptian ports reached 6.6 million containers compared to 6.2 million containers of the same type in 2009 while providing storage services, cargo handling, customs clearance and other import and export services. Dry ports provide an additional means to bridge the gap between the expected capacity of the port and the expected demand as a result of the expected increase that reaches up to $4.8 \%$ of the size of 
imports and exports over the next twenty years. The six dry ports which are strategically located in Egypt (which will be accessible via only one land road to offer an easy access across all land roads and railways) require a range of improvements in the services offered to become an integrated logistics center used to carry out effective trading operations at a lower cost [2].

Maritime and related logistical services play a vital role of foremost significance in the Egyptian economy with, on average, Egyptian ports handling nearly $65 \%$ of the country's exports. Maritime services and relative logistics are essential to a massive number of sectors in the economy because of their link to both exports and imports. Improving the efficiency of maritime transport and related logistics can have significantly positive spillover effects on encouraging private investments, trade flows, and subsequently enhancing production and job creation in almost every sector in the economy, reducing costs of imports for producers and consumers, and increasing government revenue from port services [3].

The objective of this study is to declare the risk of opening of the North Pole route on the Suez Canal and how it decreases the Suez Canal revenue which directly affects the Egyptian economy. Then, this study will discuss the methods of overcoming this risk.

\section{Research Problem}

Due to the importance of the Suez Canal on the Egyptian economy, it will be threatened by the opening of the North pole route in the future. Therefore, this paper introduces some proposed solutions to counter these threats.

\subsection{Research Questions}

(a) What is the current situation for Suez Canal?

(b) What is the expected impact of the opening of North pole route on Suez Canal?

\section{Research Methodology}

This research is descriptive research and using the following procedures:

(a) Literature review for previous study and previous information including :

- Importance of Suez Canal.

- North Pole route.

(b) Meta-analysis for the rate of vessels passing through Suez Canal.

(c) Presenting suggestions to counter the threats of North Pole route on Suez Canal.

\section{Literature Review}

The researcher has studied the available sources about the Suez Canal and the North Pole route which has been discussed as follows:

\subsection{Importance of Suez Canal}

It is historically registered in 1874 B.C. that Egypt was the leading country to dig a man-made channel over its territory to connect the Mediterranean Sea to the Red Sea through the Nile River and its branches. That channel was deserted and reopened various times then later named "The Suez Canal”. It was opened for international navigation on the 17th of November 1869 A.D. [1].

The Suez Canal is considered the briefest connection between the west and the east owing to its unique geographic position; it is an essential international navigation channel connecting the Mediterranean Sea at Port Said and the Red Sea at Suez. The unique geographical location of the Suez Canal makes it of distinguished significance to the world and to Egypt as well.

This significance is increasing with the development of maritime transport and world trade. The maritime transport is the least expensive means of transport, while more than $80 \%$ of the world trade volume is transported through waterways (seaborne trade). Saving in range, time and in operating expenses for ships that cross the canal solidify this significance as well [4].

4.1.1 Advantages of the Suez Canal

- It is the longest channel in the world without locks 
as shown in Fig. 1.

- The incidents are nearly nil compared with other waterways.

- Navigation goes all day and night.

- The channel is subjected to be expanded and deepened when required, to adapt to the advancements in vessel sizes and tonnages.

- With the adoption of the VTMS (Vessel Traffic Management System) (a system relying on the most up-to-date radar network), vessels can be observed and kept track on each spot of the channel and interference in emergency situations can be taken.

\subsection{North Pole Route}

Global climate change is presenting new chances for international transportation networks, particularly with a tendency to recede ice around the North Pole. In case that this tendency proceeds, parts of the Arctic could be utilized more dependably on navigation, at least through summer months and for longer periods of time as shown in Fig. 2. The major trans-arctic courses involve the North Pole route and the Northway Passway. The Northern Sea route along the arctic coast of Russia is the maritime route that is probably going to be free of ice and would decrease the maritime journey between East Asia and Western Europe from 21,000 $\mathrm{km}$ utilizing the Suez Canal to $12,800 \mathrm{~km}$, cutting passing time by 10-15 days and the northwest passage crossing Canada's Arctic Ocean could be applicable on a constant basis by 2020, extraordinarily decreasing

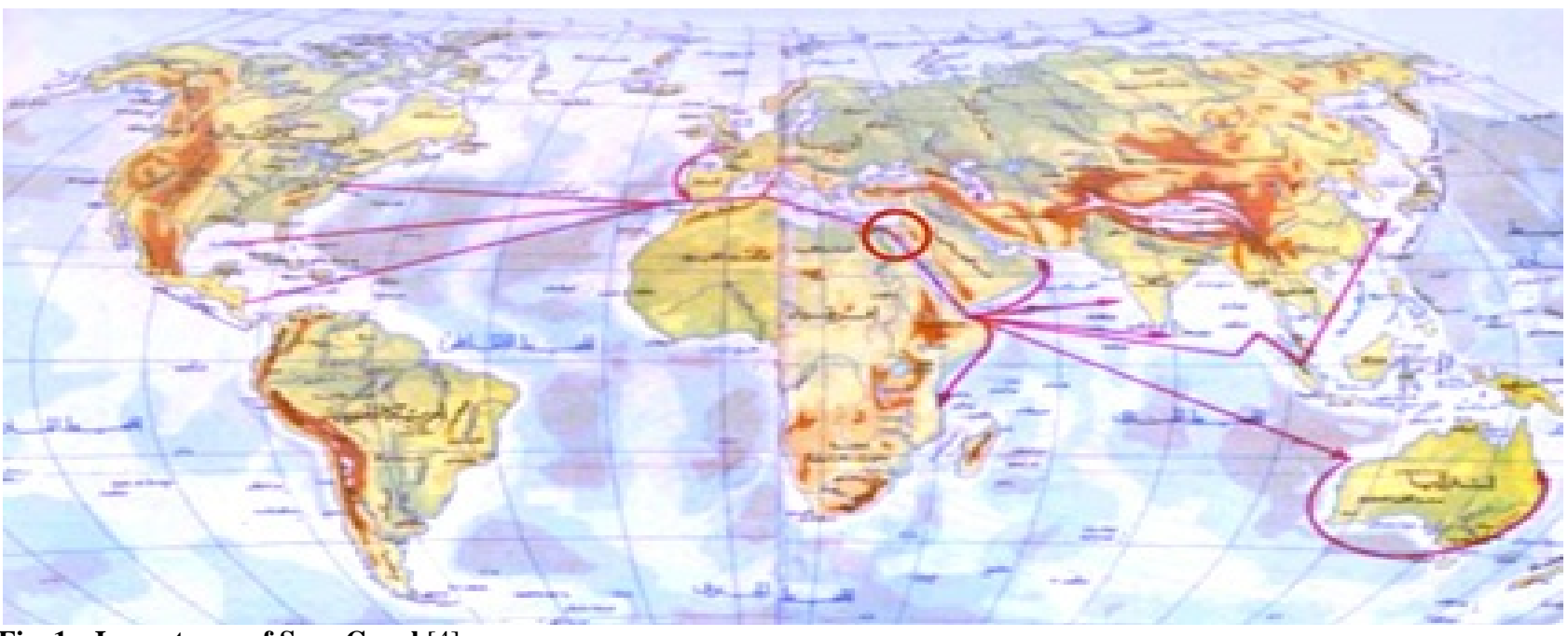

Fig. 1 Importance of Suez Canal [4].

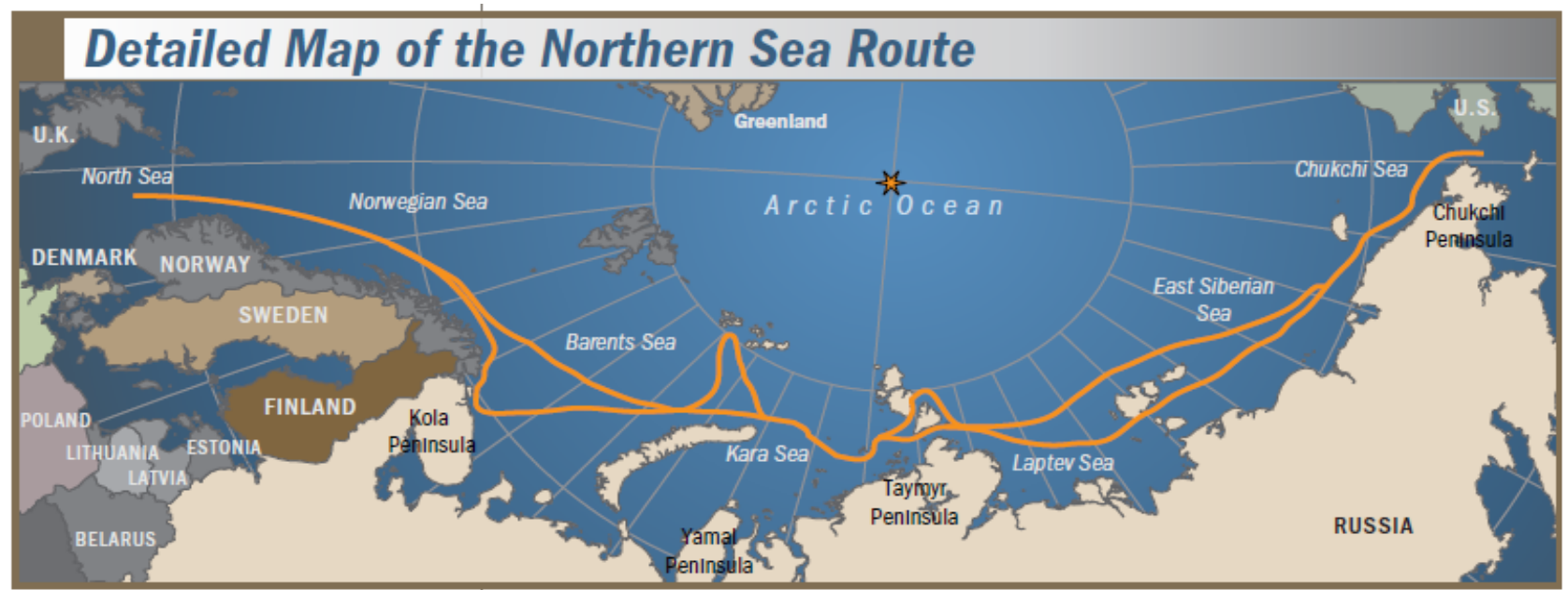

Fig. 2 North pole route [5]. 
maritime shipping distances. The maritime journey between East Asia and Western Europe would take around 13,600 km utilizing the Northwest Passage, whilst taking 24,000 km utilizing the Panama Canal [5].

According to HalvorSchoyen and SveinBrathen, 2010, studies about advantages achieved through energy efficiency enhancements owing to a shorter course (the North Pole route) may substitute the disadvantages brought about by uncertainty connected to both the NSR and the course through the Suez Canal. The distinction in navigational distance from North West Europe (London) to Far East (Yokohama) is 4,200 nm, which for 15 knots constant speed equals to a distinction in time at sea of around 12 days, all other factors being correspondent for the two courses [6].

As per the Congressional Research Service report, China runs a trade overflow the world's three main economic centers: (1) The United States, (2) The European Union, and (3) Japan. Since 2000, the United States has undertaken its biggest bilateral trade deficiency with China ( $\$ 201$ billion in 2005, a 25\% rise over 2004). In 2003, China supplanted Mexico as the second biggest source of imports for the United States. China's share of U.S. imports was $14.6 \%$ in 2005, in spite the fact that this ratio still fails to reach the level of Japan's 18\% of the early 1990s. The United States is China's biggest overseas market and second biggest source of foreign direct investment on accumulative basis. U.S. exports to China have been developing quickly as well, though from a low base [7]. In 2004, China supplanted Germany and the United Kingdom to turn into the fourth biggest market for U.S. commodities and continues to be the quickest developing U.S. major export market. China is purchasing vigorously from its Asian trading partners especially in precise machinery, electronic composition sand raw materials for industrialization. China is running trade deficiencies with Taiwan and South Korea and has turned into a main buyer of merchandise from Japan and Southeast Asia. This situation manifests that the effective trade movement is between Europe and Far East and Far East to Pacific [8].

\section{Analysis and Substantiation}

\subsection{Opening of North Pole Route}

The North Pole route came to light because of the climate change as several researchers conclude that rising temperatures are causing ice to melt in the northern hemisphere. When the various effects of climate and weather variability and change are introduced into computer models that project atmospheric temperature patterns, the results clearly show that the average temperature in the Arctic region could rise by $3-9{ }^{\circ} \mathrm{C}$ over the next hundred years, which is double the increase expected in other parts of the world during the same period. Warming would cause an enormous quantity of ice to melt and it is believed that ice could disappear altogether from large areas of the ocean during the summer months in the coming decades as shown in Fig. 3. Extensive melting has already begun, especially in areas of thick perennial ice. Computer models show that the surface area of ice at the end of summer could contract by $15 \%$ to $40 \%$ by the year 2050, accompanied by reductions in average thickness of up to $30 \%$ in the same period. Indications are that the Arctic Ocean could be relatively free of ice towards the end of the century. Ice will still form during wintertime but it will be a comparatively thin layer and ice-breakers will be able to force a passage through it. Ocean currents will probably cause the ice to drift away from eastern regions of the Arctic Ocean, which would ease sailing conditions [9].

\subsection{Drop of Suez Canal Revenue}

The Suez Canal suffered from a huge decrease in its revenue in the last decade due to the following causes:

- The collapse of the world trade.

- Passing some of ships through the Cape of Good Hope. 


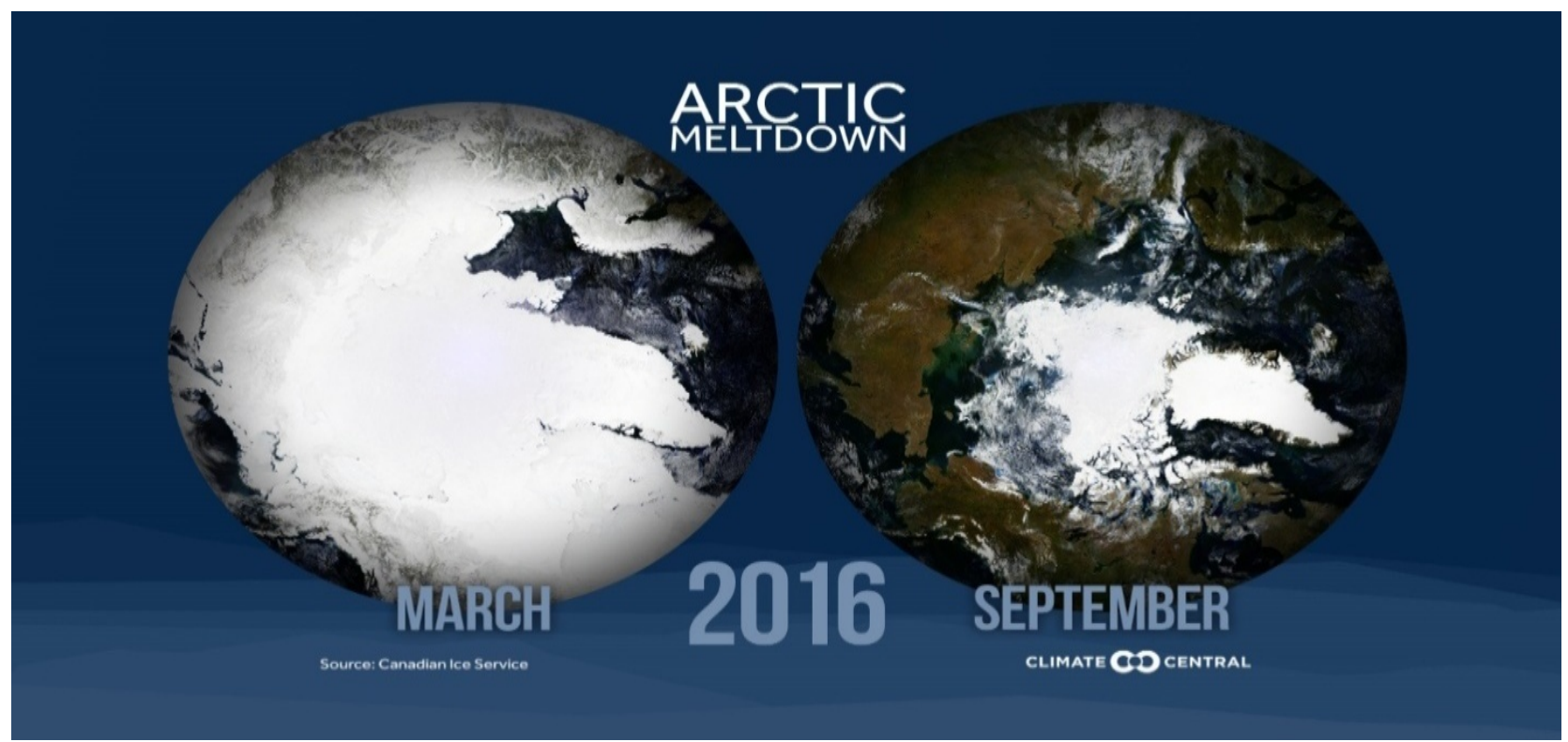

Fig. 3 Arctic ice meltdown in summer 2016 [10].

- Opening of the North Pole route.

Firstly, due to the declining of the world trade, the number of ships passing through the Suez Canal has decreased which affected the Suez Canal's revenue. Secondly, some of ships headed to pass through the Cape of Good Hope, despite of its long path comparing with the Suez Canal route but its cost is less than the cost of passing through the Suez Canal route for long distance travel ships. Thirdly, shipping lanes through the Arctic Ocean will put the Suez Canal out of business soon, as global warming will make these frigid routes much more accessible than ever imagined by melting an unprecedented amount of sea ice during the late summer.

Fig. 4 shows the comparison between two maritime routes for transporting cargoes from the Far East to Europe. The shortest route to travel from China to Rotterdam is by using the North Pole route which can save up to 13 days. The philosophy applied in the shipping industry is that the reduction in route distance will automatically reduce the total travel time, ultimately reducing the total fuel consumption, bunker fuel cost and vessel operating cost respectively. Consequently, the amount of emissions produced by ships will definitely be reduced. Finally, the shipping companies' profit margin will dramatically increase without any argument.

\subsection{Statistics for Suez Canal}

From the previous reasons, it can be noticed that the most important reason which affected the Suez Canal revenue and will play a dramatic role in decreasing the Suez Canal revenue in the future is the opening of the North Pole route. The following statistics prove that the number of vessels and the total cargo weight in Suez Canal already decreased through the last few years especially in the summer months which are from June to October.

5.3.1 Number of Vessels Passing through Suez Canal

The following Fig. 5 shows the total number of vessels passing through the Suez Canal in both directions (South/North-North/South) from June to October in 2015 and 2016.

It is clear that the total number of vessels passing through the Suez Canal in summer months decreased in 2016 comparing with the same months in 2015. This is an expected statistic as the number of vessels passing through the North Pole route increases gradually through the last few years since the opening of this route. 


\section{China's New Shipping Frontier}

How the new Northern Sea route compares to the traditional Suez Canal route

\section{NORTHERN SEA ROUTE}

Travel time

35 days

Dangers

Icebergs

Travel window

July to November

Container-carrying vessels

One this year

\section{SUEZ CANAL ROUTE}

Travel time

48 days

Dangers

Access to Suez Canal under

question with upheaval in Egypt

Travel window

Year-round

Container-carrying vessels

17,000 last year

Fig. 4 China's New Shipping Frontier [11].

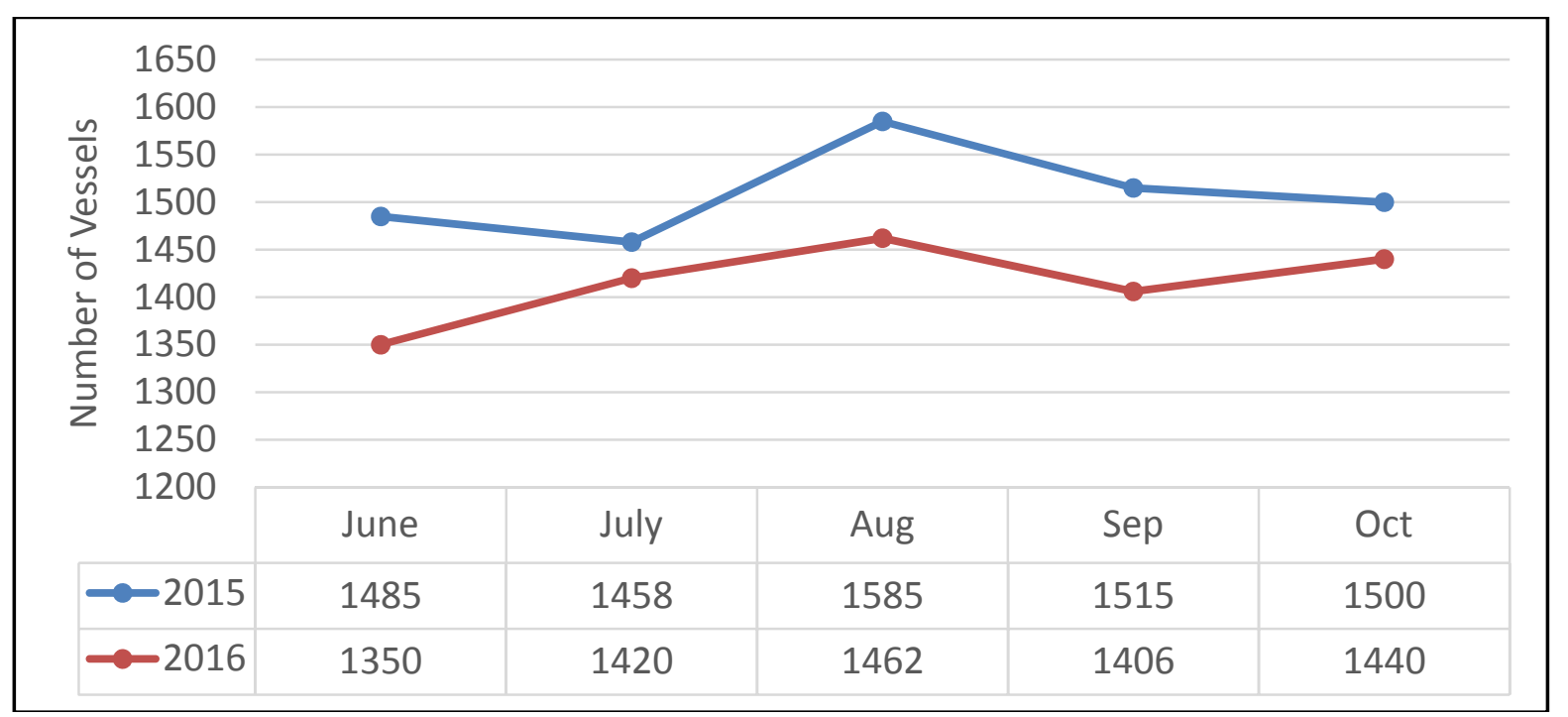

Fig. 5 Number of vessels passing through Suez Canal.

Source: Authors derived from various sources.

\subsubsection{Total Cargo for the Vessels that Passed through} Suez Canal

Fig. 6 illustrates the total cargo for the vessels that passed through Suez Canal in both directions (South/North-North/South) from June to October in 2015 and 2016.

One can see in Fig. 6 that the total cargo for vessels that passed through the Suez Canal in the summer months is declined in 2016 when it is compared with 2015 due to the decreasing of the number of vessels passing through the Suez Canal in that time. Thus, the North Pole route plays a huge role in decreasing the number of vessels and the total cargo which directly affects the Suez Canal revenue.

\subsubsection{Total Cargo from Far East}

By increasing of international trade between the Far 


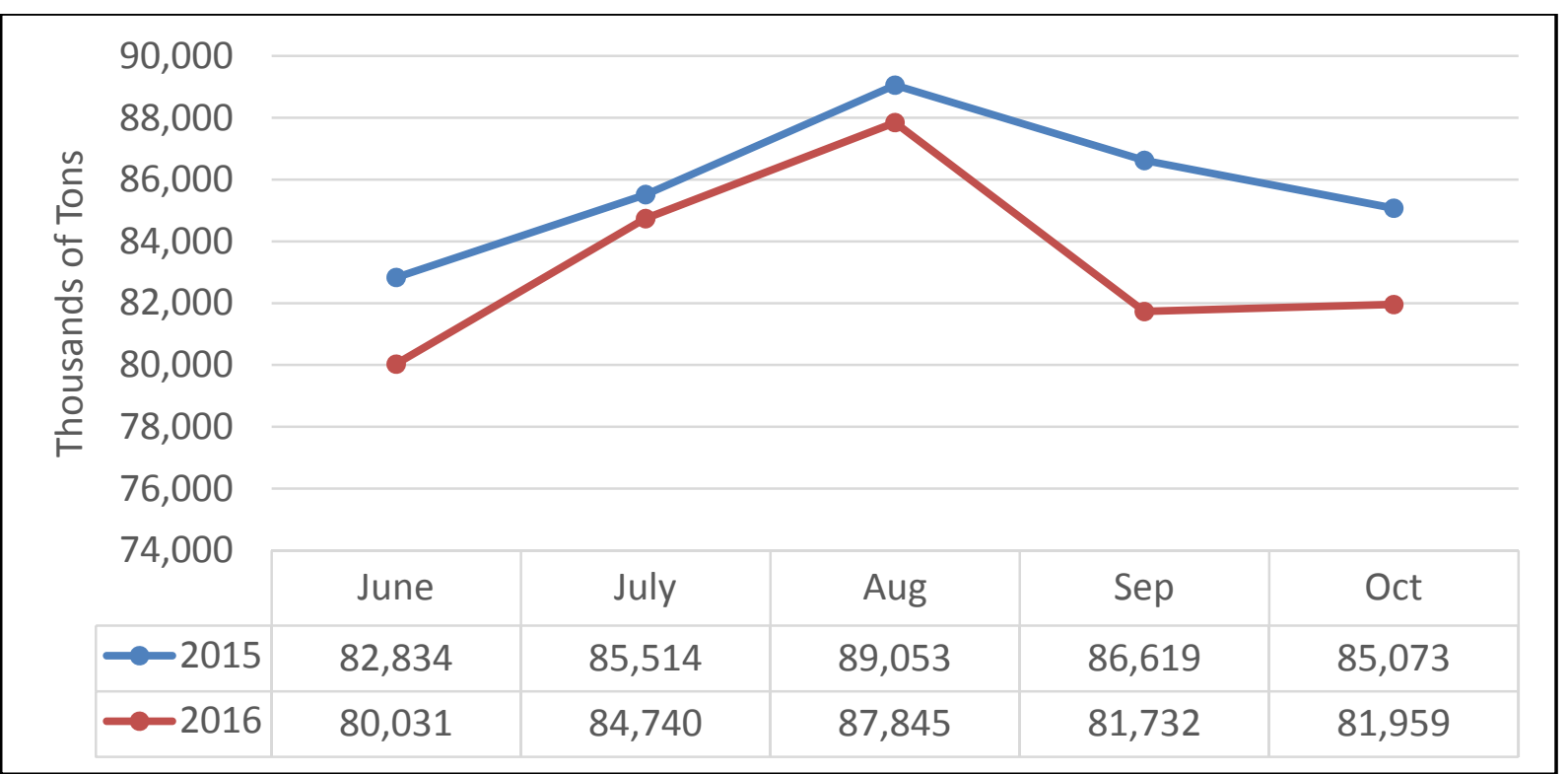

Fig. 6 Total cargo for the vessels that passed through Suez Canal.

Source: Authors derived from various sources.

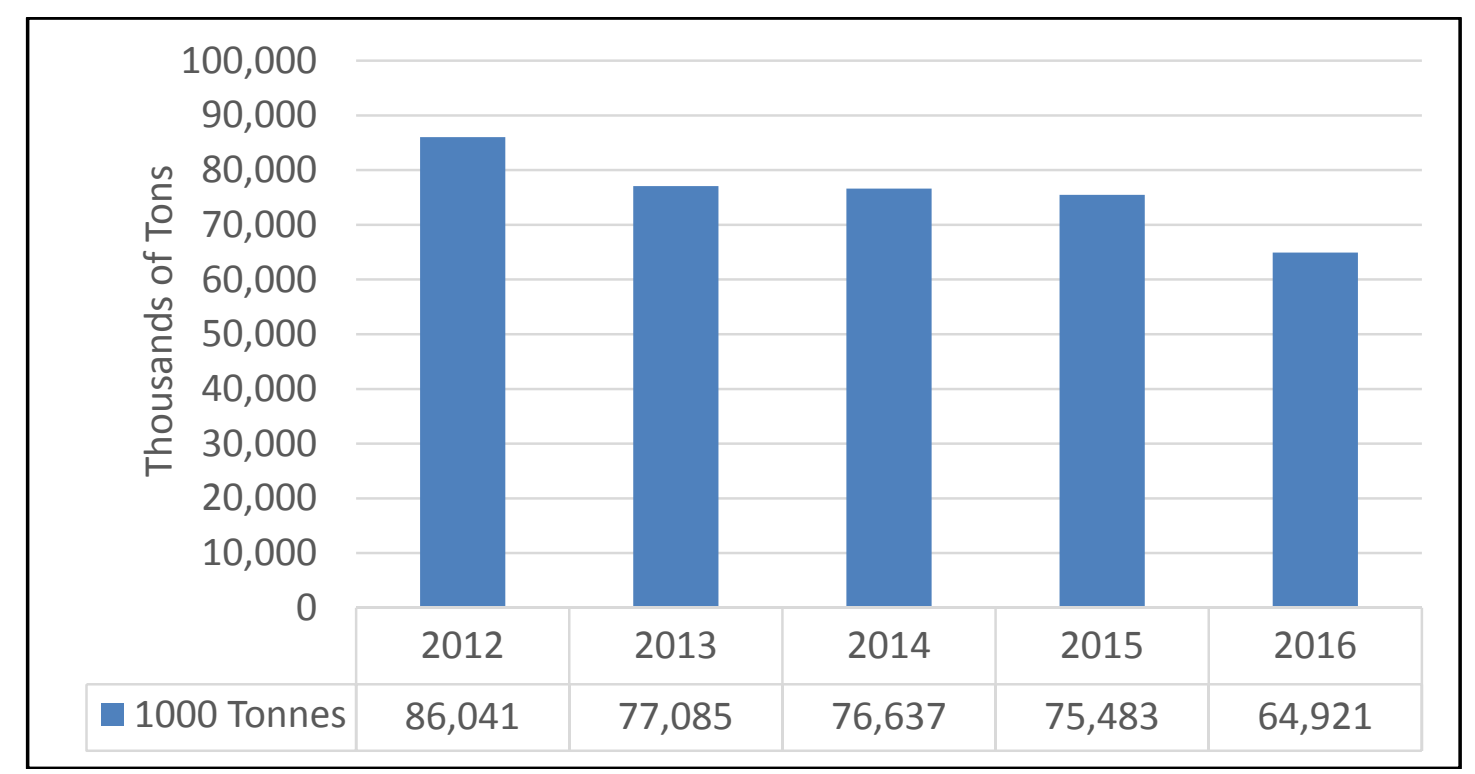

Fig. 7 Cargo related to Far East.

Source: Authors derived from various sources.

East and Europe, the shipping companies began to sail through the North Pole route due to the great saving in fuel consumption, bunker cost, operating cost, emissions and journey time. Thus, these companies went away from the Suez Canal which has a dramatic effect on the Suez Canal revenue.

Fig. 7 shows the total cargo for vessels passing through the Suez Canal which have Far East in their origin or destination from 2012 to 2016.
One can notice in Fig. 7 that the number of cargo for vessels related to the Far East declined gradually from about 86 to 64 million tons within 5 years. This decrease indicates to heading some of shipping companies to sail through the North Pole route and avoiding the Suez Canal route to increase their profit. By contrast, the revenue of the Suez Canal had a dramatic reduction due to the avoiding of shipping companies to the Suez Canal route. 
By 2050, Laurence C. Smith and Scott R. Stephenson at the University of California, say that common vessels ought to have the ability to travel effectively along the northern sea course and reasonably ice-reinforced vessels ought to be able to take the briefest convincible course between the Pacific and Atlantic Oceans, crossing over the pole itself. The easiest time would be in September, when annual sea ice cover in the Arctic Ocean is at its lowest range [12].

\section{Conclusions}

One can conclude from this research and the illustrated figures that the opening of North Pole route has threaten the Suez Canal future as it began to affect the revenue of Suez Canal. Nowadays, the shipping companies sail their ships through the North Pole route in the summer months only. In the near future, by the effect of global warming the ships will be able to sail in the North Pole route throughout the year which means that the Suez Canal will be out of business.

\section{Suggestions}

Our suggestion to counter these threats of North Pole route is that there must be a comprehensive change in the Suez Canal policy and reconsidering the applied pricing policy in accordance with the international markets and the expected changes in maritime transport routes.

- The necessity to link the Suez Canal Authority with maritime transport sector, where it is a part that cannot be separated from the sector. Furthermore, when dealing with both the Suez Canal and the Egyptian ports only one entity should be addressed.

- Suez Canal Authority should be concerned with, re-evaluate and re-structure its affiliated companies to maximize the benefit from them. One of these affiliated companies is the arsenals which belong to it. These arsenals can be organized and restructured then put in the stock market to reap huge profits from these companies. It is necessary for the companies, which are affiliated to the Suez Canal Authority, to be privatized while retaining a share of them with the Authority, reconsidering the admission of foreigners to the Egyptian maritime market and giving privileges where, at least, foreigners and Egyptians are treated evenly when investing in maritime transport as well.

- The possibility of benefiting from the potentials and the contributions of departments and companies of the Suez Canal Authority, maximizing their revenues and the possibility of renovating the industry of shipbuilding and repairing in the region as well as its subsidiary industries, besides establishing well-managed companies for all ships' supplies.

- Taking advantage of Suez Canal region through the establishment of projects with added value for maritime transport industry. These projects serve the vessels passing the Canal which need temporary maintenance in addition to founding logistics centers and P\&O Clubs to offer service for vessels which may be exposed to accidents while crossing the waterway. It is possible to establish places for maintenance agents and spare parts for maritime transport, centers to employ sailors as some passing ships need sailors during their journey, emergency hospitals as well as medical evacuation systems for ships in transit.

- Finally, establishing a large maintenance center in the cities covered by Suez Canal region and arsenals for building and repairing ships. However, this will not have an economic payoff unless existing ports are given attention, raised their capacity and converted into hub ports as well as establishing projects within the port.

\section{References}

[1] Alexandria Crewing Agency. 2013. Available online at http://www.acaegypt.com/en/egypt-a-its-maritime-industr y.

[2] Industrial Development Authority. 2014. Available online at

http://www.ida.gov.eg/Arabic/Why_Egypt/Pages/infrastr ucture-and-logistics.aspx.

[3] Ghoneim, A F. 2007. "Maritime Transport and Related Logistics Services in Egypt.” Switzerland: International Centre for Trade and Sustainable Development. 
[4] Suez Canal Authority. 2013. Suez Canal Service, Available online

at http://www.suezcanal.gov.eg/sc.aspx?show=10.

[5] Claes, L. R. 2008. The Northern Sea Route. Sweden, Norden Association's Yearbook for 2008.

[6] Rahman, N. S. F. A. 2014. "Effect of the Northern Sea Route Opening to the Shipping Activities at Malacca Straits." International Journal of e-Navigation and Maritime Economy 1: 85-98.

[7] Backhouse, R. E., and Medema, S. 2008. "Definition of Economic.” The New Palgrave Dictionary of Economics 2: 20-2.

[8] Perry, C. M., and Anderson, B. 2012. New Strategic
Dynamic in the Arctic Region. United States of America: The Institute For Foreign Policy Analysis.

[9] Report of a working group. 2006. "North Meets North Navigation and the Future of the Arctic.” The Ministry for Foreign Affairs, Iceland.

[10] Climate Central. 2016. Available Online At http://www.climatecentral.org/gallery/maps/2016s-arcticsea-ice-melt-season-in-8-seconds.

[11] Northern Sea Route Information Office, National Snow and Ice Data Center, 2013.

[12] The Guardian. 2013. Available online at https://www.theguardian.com/environment/2013/mar/04/ ships-sail-north-pole-2050. 